\title{
Analysis of Pre-service Mathematics Teachers' Teaching Strategy Knowledge of Geometric Formulas
}

\author{
Meltem Koçak, Yasin Soylu* \\ Department of Elementary of Mathematics Education, Faculty of Kazim Karabekir Education, Ataturk University, Turkey
}

Copyright $\subseteq 2017$ by authors, all rights reserved. Authors agree that this article remains permanently open access under the terms of the Creative Commons Attribution License 4.0 International License

\begin{abstract}
The purpose of this study is to analyze the teaching strategies of the prospective teachers of mathematics for elementary school in relevance with the geometry formulas. The participants of the study are constituted by six senior students of the program of mathematics teaching for elementary school. In this study, where the qualitative research approach is employed, the method of case study is used and the data of the study were aggregated with the techniques of semi-structured interview, observation and analysis of documentation. The data of the study were analyzed by the virtue of the technique of content analysis. With regard to the data obtained from the study, it was seen that the prospective teachers were the supporters of making students find the logic of the formulas by explaining them, instead of making them memorize, while they were teaching the mathematical formulas of which logical reason they could explain. On the contrary, it was found that the prospective teachers were the supporters of making students memorize directly the formulas of which logical explanation they could not explain. Besides, even if the prospective teachers could explain the meaning of the given formula, they could not make teaching explanations enough while they were teaching this formula.
\end{abstract}

Keywords Geometric Formulas, Preservice Teacher, Teaching Strategy Knowledge

\section{Introduction ${ }^{\mathrm{i}}$}

In order for students to understand geometry, they need to understand the formulae and the relationship between the formulae and geometric shapes [1]. Many students have stated that they believe problems requiring formulae are difficult to solve and they cannot learn the logical reasons behind the formula and the most difficult thing in geometry is the formulae since they have to memorize them [2]. Therefore, when teaching mathematical rules and formulae importance must be given to understanding and reasoning instead of trusting the memorization capabilities of students
[3]. However, in teaching mathematics, generally there is a way of teaching when mathematical rules and formulae are disregarded, the conceptual bases of formulae and rules are not stressed enough and formulae and rules are forced to be memorized [3-6]. This type of teaching obligates students to memorize the formulae they are using and therefore cause them to mix up the formulae quite often and to make mistakes $[4,5,7,8]$.

However, the developments in mathematics teaching in recent years underline a mathematics teaching through activities enabling students to find these formulae and rules and to create the main concepts by themselves rather than having them memorize a lot of mathematical formulae and rules or easily providing students with them [9]. In this case, a lot of responsibilities fall on the shoulders of teachers. For teachers to be able to give educational explanations at a conceptual level, first, they need to understand mathematics at the conceptual level themselves. When teachers do not have a sufficient level of understanding in mathematics, they immediately take an escape route to make students memorize the rules. These escape routes are such as to reinforce the idea belonging to students that mathematics is full of meaningless and nonsensical rules [6]. Upon examining the mathematics teacher training system around the world, it is observed that pre-service teachers are first given mathematical information, and then they work on teaching this information. The reason for this is clear: nobody can teach something that he/she does not know, thus, preservice mathematics teachers should know mathematics at the level that allows them to teach it [10]

Although it is a prerequisite of teaching for a teacher to know a field or a subject very well, it is not sufficient for a successful education [11]. In this direction, beyond having a good command of their own field, teachers should have knowledge of how to teach their lesson, how to transmit it to students and get to the level of students [12]. In this context, the knowledge of teaching strategy gains importance.

Accordingly, more than the teacher being an expert in his field, he needs to know how to start the lesson for his students to acquire the intended objectives, which examples, 
materials, teaching method and techniques can be effective and needs to decide how these can be used properly, all of which are defined as teaching strategy knowledge [11] Most studies carried out on this subject have shown that pre-service teachers fail to conceptually explain the given situations although they know what the rules and methods are in general and how to apply them [6], and their instructional explanations in order to eliminate student mistakes are not sufficient [13]. Therefore, it is focused on what kind of information a teacher needs to have in order to teach effectively in a classroom and a lot of studies are conducted on the teachers' teaching strategy knowledge [14-18].

However, the conducted studies indicate that many teachers do not know how to regulate the teaching of mathematics, so they cannot convey their mathematical knowledge to students due to their lacking of teaching models and the insufficiency of examples, and they cannot communicate with students [19]. In this context, teachers' knowledge of how to use their teaching knowledge, how to transfer their knowledge to students and how to make contact with the student during the course has attracted the attention of many researchers [20-22].

In this study within this scope, it was aimed to analyze the teaching strategy knowledge of pre-service elementary school mathematics teachers that play a role in transferring mathematical formulae to students. When the literature was analyzed, no study on teaching strategy knowledge which was directly related to mathematical formulae was encountered, but it was seen that formulae were implicitly addressed in some studies. In other words, formulae do not form the basis of these studies encountered in the literature [1,5,6,23-26]. Thus, this study has importance both in making contribution to the literature as well as making pre-service teachers aware of how effective they can teach the formulae.

Furthermore, considering that in today's education, students memorize mathematical formulae and thus have difficulty in the solution of the problems requiring formulae $[5,7,9]$, and teachers teach based on memorization, without emphasising the meaning and logic of the formulae $[6,26]$, this study is important in that it gives an idea to teachers of the logic and teaching of the geometric formulae included in the curriculum.

\section{Method}

In this study, in which the qualitative research approach was employed, the method of the case study was used. Qualitative research is a research approach in which the research process is flexible; data are thoroughly analyzed in this process and clearly expressed at the end of the study [27]. In the method of the case study, it is aimed to reach data diversity which is rich and can confirm each other by using more than one means of data collecting [28]. Also, in this study, qualitative data, which were collected with the use of several data collecting tools such as interview, observation and documentation analysis, were exerted in a realistic and complete way. Therefore, the method of the case study was preferred in this study.

\subsection{Participation}

The participants of the study consisted of 10 elementary pre-service mathematics teachers who were randomly selected by the random sampling method. While determining these 10 pre-service teachers who were included in the study, the subjects included in the 2014-2015 mathematics curricula were randomly distributed to 84 pre-service teachers from two separate classes.

These pre-service teachers who were included in the study and who were final year students in the elementary mathematics teaching program are a suitable group in terms of achieving the purpose of our study because these pre-service teachers took all of the teaching courses (Special Teaching Methods, Mathematics Teaching Seminar, etc.) that are effective in the development of teaching strategies knowledge that plays a role in transferring their knowledge to students. When it was considered that these pre-service teachers would give lectures at schools in the future, determination of these pre-service teachers' competencies and shortcomings related to the teaching of mathematical formulae was thought to be more appropriate to the purpose of the study.

While explaining the findings of the study, the real names of the pre-service teachers were coded as $T_{1}, T_{2}, T_{3} \ldots T_{10}$ due to the reasons of confidentiality.

\subsection{Data Collection}

In this study, semi-structured interview and observation were used together and the acquired qualitative data were presented in a realistic and holistic way.

In a semi-structured interview, the researcher can ask additional questions according to the course of the interview to obtain more in-depth information, can intervene in the situation when the interviewee misunderstands the question, and more detailed information can be obtained by asking the interview questions from different aspects [29]. In the form, which is prepared for the semi-structured interview, particular attention was paid to choosing the formulae which were included in the program of mathematics course for secondary schools in 2014-2015. It is because the knowledge of teaching strategy is information related to conveying the subject that is going to be taught by the teacher [11]. After determining the formulae to be included in the interview form, two teachers and two experts were asked for their opinions about whether these formulae were suitable for the purpose. Various additions and exclusions were made in the formulae to be included in the interview form in line with the suggestions and opinions of the experts and teachers. After finalizing the formulae to be included in the interview form, teaching scenarios were created to determine the pre-service 
teachers' teaching strategy knowledge of these formulae. In this form, the reason why the teaching scenarios were used is both to make the pre-service teachers feel comfortable and give more sincere answers to the questions, and to determine their demeanors and reactions by reflecting the events which are potential for them to encounter with when they become teachers in the future. While creating the teaching scenarios, attention was paid that these are questions contacting with the points of which method, technique and strategy will be used by pre-service teachers, how they will correct the mistakes of students and how they will eliminate the misconceptions while they are conveying the given formulae to students.

After preparing the scenario questions, two experts were asked for their opinion about whether these questions served the purpose of determining at what levels pre-service teachers' teaching strategy knowledge was. The shortcomings included in the interview form were corrected in accordance with the expert opinions, and the option of "How would you teach if you were?" was added to all scenario questions. Furthermore, the option "If your answer is no, what kind of a path will you follow in teaching the surface area of the right circular cylinder?" was added to the first question and "If you were teacher Selin, how would you correct Ali's mistake?" was added to the option of the second question related to the teaching of the formulae to be included in the interview form in accordance with the opinions and suggestions of the experts and teachers. In this way, it was ensured that pre-service teachers gave more detailed answers to these teaching scenario questions, and an attempt to minimize the possibility of giving cursory answers was made. The interview form was finalized by making necessary corrections in some scenario questions in accordance with the expert opinions.

In studies carried out on pre-service teachers' teaching strategy knowledge, it was observed that pre-service teachers' statements regarding the question of "How would you teach?" and their in-class practices were not always consistent with each other [16]. In this context, determining whether pre-service teachers made exaggerated statements during interviews or making written statements is considered as a difficult procedure [29]. Therefore, it was needed to make course observations in addition to the interview performed to determine whether pre-service teachers' written and verbal statements were consistent with their teaching practice and to obtain first-hand and more in-depth knowledge. In the observation process, a total of six teachers were observed within the scope of the Mathematics Teaching Seminar course in a way that two pre-service teachers would teach each subject from among the subjects related to the formulae included in the interview form. Thus, an attempt to determine whether pre-service teachers' statements regarding the question of How would you teach? and their in-class lectures were consistent was made. In other words, pre-service teachers were observed during lectures for the best determination of how they taught mathematical formulae in addition to the interviews made despite the possibility that pre-service teachers would not reflect the truth or make exaggerated statements in the interviews [29]. Thus, the opportunity to examine how pre-service teachers taught the subjects related to the given mathematical formulae in a closer and realistic way was achieved in the study. Observation process was conducted within the scope of the "Mathematics Teaching Seminar" course.

During the observation, pre-service teachers' lectures were videotaped by receiving their permission. In this way, an attempt to increase the reliability of the study was made by getting the chance of listening to the course again and catching the points missed during the course. An attempt to increase the reliability of the study was also made by transferring the data collected during the observation in a clear and detailed way. Furthermore, the course observations of pre-service teachers were made by a researcher and an expert as a part of the study. Thus, the opportunity of comparing the data obtained was achieved in addition to taking measurements to avoid the possibility that any of the observers was prejudiced. This is important in terms of ensuring the internal validity of the study.

Furthermore, it was attempted to determine whether the methods implemented were consistent when the explanations made by pre-service teachers in interviews with regard to the teaching of the given formulae and classroom practices were observed.

\subsection{Data Analysis}

The data obtained to determine pre-service teachers' teaching strategies knowledge of the given mathematical formulae were analyzed by the descriptive analysis technique. In the descriptive analysis, it is aimed to present the findings obtained to readers in an organized and interpreted way. Thus, the data obtained are firstly described in a clear and systematic way, then these descriptions are explained and interpreted, their cause and effect relationships are analyzed, and certain results are achieved. In this process, direct citations are often included to reflect the opinions of individuals who are interviewed or observed in a remarkable way [30].

In this study, an attempt to present a more detailed image of the data obtained was made by including direct citations from the instructional statements of pre-service teachers they made during the interview and from the observation results. Furthermore, the pre-service teachers' teaching strategies knowledge was thoroughly examined by supporting the data obtained by the document analyses. Therefore, the descriptive analysis technique was preferred.

In this context, the data of the semi-structured interview conducted with the pre-service teachers were simplified in line with the objective of the study and presented in a clear and intelligible way for the reader. In addition to this, in order to present and describe the data obtained in a more detailed way, the quotations from the interview data were supported by the observation data.

Moreover, direct citations regarding the statements of the 
pre-service teachers were included, the statements of the pre-service teachers were translated into English, the translated statements were rewritten without making any change, and a citation was performed in this way.

\section{Findings and Interpretation}

The findings obtained from the teaching scenarios and observation reports are included in this section to be able to determine the pre-service teachers' teaching strategy knowledge of geometry formulae.

\subsection{Finding and Interpretation Regarding the Area of the Cylinder Formula}

In the interview conducted with 10 pre-service teachers for the purpose of determining the pre-service teachers' teaching strategy knowledge of the surface area of the cylinder formula, all pre-service teachers stated that they would use the development of the cylinder to teach the surface area of the cylinder formula to students, and 9 of these pre-service teachers could properly apply it in their written statements. Furthermore, when pre-service teachers' written statements were analyzed, it was observed that 5 pre-service teachers stated that it was not necessary to give the formula to students, and 5 pre-service teachers stated that the formula should be given to students providing that its logic is explained. In this context, when pre-service teachers' written and verbal statements were analyzed, it was seen that all pre-service teachers emphasized that it was not necessary to give the surface area of the cylinder formula by heart because a student who exactly understood what the concept of the surface area was could answer a question requiring finding the surface area of the cylinder without memorizing it. The written statement of $T_{4}$ among these pre-service teachers is presented in Figure 1.

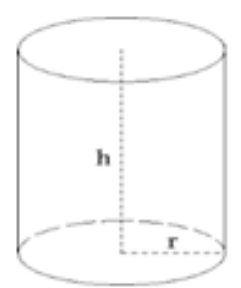

Teacher Ayşe directly showed the surface area formula of the right circular cylinder, the shape of which is given on the side, as $2 \mathrm{r}(\mathrm{r}+\mathrm{h})$. Student Sena posed a question of "Teacher, I memorize this formula every time but I forget it, what should I do not to forget?"

\section{a) If you were teacher Ayşe, how would you answer this question of Sena?}

b) If you were teacher Ayşe, would you teach this formula to students while explaining the surface area of the right circular cylinder? If your answer is yes, please explain in detail how you would teach the surface area of the right circular cylinder.

\section{c) If your answer is no, what type of path you would follow while explaining the surface area of the right circular cylinder to students?}

"Teacher Ayşe directly showed the surface area formula of the right circular cylinder, the shape of which is given on the side, as $2 \mathrm{r}(\mathrm{r}+\mathrm{h})$. Student Sena posed a question of "Teacher, I memorize this formula every time but I forget it, what should I do not to forget it?"

a)If you were teacher Ayşe, how would you answer this question of Sena?

b)If you were teacher Ayşe, would you give this formula to students while explaining the surface area of the right circular cylinder? If your answer is yes, please, explain in detail how you will teach the surface area of the right circular cylinder.

c) If your answer is no, what type of path you will follow while explaining the surface area of the right circular cylinder to students?

a) I would say that it is remembered more easily by unfolding the cylinder.

b) +No, I wouldn't. I would follow a path that will make students comprehend it.

c) While teaching the surface area of the right circular cylinder to students, I would first teach them the development of the cylinder. Then, I would try to make them comprehend that it consists of two circles and one rectangle. 


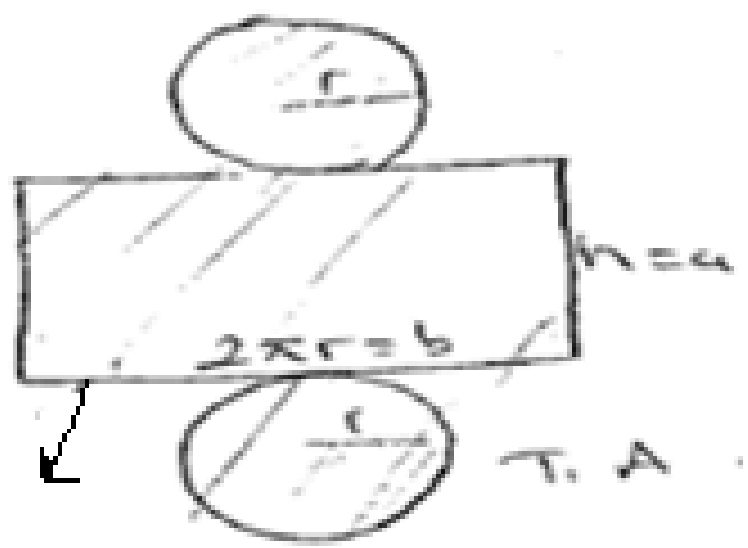

It is attempted to make students comprehend that the circle's perimeter is the length of it.

Then, I would make them remember that the area of a circle is $\pi r^{2}$ from previous subjects. It is reminded that the area of a rectangle is the multiplication of the short side and long side. The students are made to understand that one side is equal to the perimeter of the circle.

Floor Area $=$ sum of the areas of two circles + area of the rectangle

$=2 \pi r^{2}+a \cdot b$

It is attempted to be made without giving the formula.

Figure 1. Pre-service teacher $\mathrm{T}_{4}$ 's written statement regarding the surface area of the cylinder formula

Upon examining Figure 1, it is seen that pre-service teacher $\mathrm{T}_{4}$ will teach using the development of the cylinder while teaching the formula given, and thus, students will not have to memorize the formula, and consequently he/she will not give the formula. This approach of the pre-service teacher is important in terms of simplifying the surface area formula, which is an abstract concept, to a level at which students can understand it. Upon the written explanation made by pre-service teacher $T_{4}$, in a face-to-face interview held with the pre-service teacher in order to learn the opinions of the pre-service teacher on the surface area formulae more in-depth, the pre-service teacher was asked whether he/she would use the same path in teaching the surface area formulae of other geometric objects. The following is the direct quotation from the explanation of the pre-service teacher with regard to this.

"I mean; we cannot apply it to all of the geometric objects. For example, we can use the unfolded form of the cylinder, but we can directly give the formula in the rectangular prism, and so on. Actually, I give the formula for the surface area of the cylinder and also show how to obtain it. For, that students unfold the object and find it each time leads to time loss. I mean, if they know the formula after learning what the concept of the surface area is, they can solve the problems without losing time."

When the explanations of the pre-service teacher were examined, it was seen that he/she emphasized in written explanations that giving the surface area of the cylinder formula was unnecessary, but stated that knowing the formula by heart would be beneficial in terms of saving time in the face-to-face interview. Similarly, when the pre-service teacher was asked about the surface areas of other geometric objects, it was seen that he/she actually said that the formulae were necessary and the strategy used with regard to the surface area formula of the cylinder would not be appropriate for the surface area formula of other objects. In this sense, it can be said that written and oral explanations of the pre-service teacher are inconsistent.

Observation data were examined in order to determine whether the explanations made by pre-service teacher $T_{4}$ on teaching the surface area formula were applied during teaching the lesson. Upon investigating the observation data of the pre-service teacher, it was seen that quite clear and comprehensive explanations were made by emphasizing what the concept of the surface area was during teaching the formula of the surface area. Furthermore, it was seen that the pre-service teacher used concrete materials while teaching the surface area formula and thus could visually present the abstract structure of the formula. The material used by this pre-service teacher in teaching the surface area formula of the cylinder is presented in Figure 2.

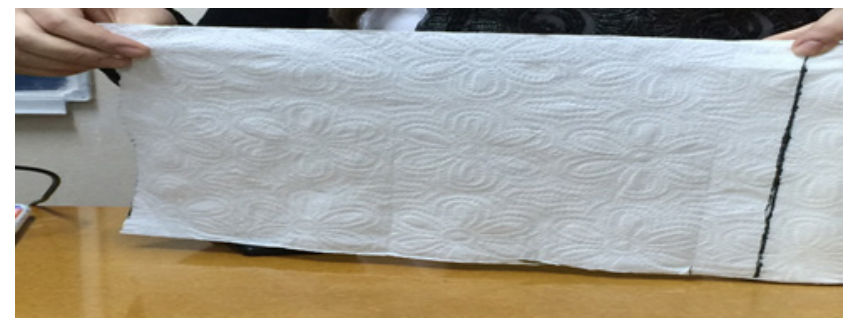

Figure 2. The material sample regarding the surface area of the cylinder of pre-service teacher $\mathrm{T}_{2}$

In Figure 2, it is seen that pre-service teacher $\mathrm{T}_{4}$ uses a napkin roll in order to express that the length of one side of the rectangle in the development of the cylinder is equal to the length of the circles forming the bases of the cylinder, and the other side is equal to the height of the cylinder. With the help of this material, the pre-service teacher had the opportunity to emphasize both the meaning of the concept of the surface area, how the surface area formula is obtained, and the development of the cylinder. In addition to this, in the observations made, it was seen that pre-service teacher $T_{4}$ achieved the solution starting from concrete materials without preferring to use the formula directly when solving examples that require finding the surface area of the cylinder. Again, when the observation data of pre-service teacher $T_{4}$ are examined, it can be said that he/she frequently follows a path from the known concepts to the unknown concepts by questioning the pre-knowledge of students and makes the teaching of abstract concepts easier with the help of concrete materials.

It is seen that the observation data of pre-service teacher $\mathrm{T}_{4}$ during teaching the lesson and the statements made in the face-to-face interview are inconsistent. The reason for this inconsistent behavior of the pre-service teacher may be that the observations of the study are performed within the 
scope of the "Mathematics Teaching Seminar" course. For, it was seen that the teacher of the mathematics teaching seminar warned pre-service teachers that they should pay attention to the conceptual understanding of the subjects they would teach, that they should not make students memorize the formulae and rules, and thus, their teaching would reflect on their lesson passing scores. In this sense, pre-service teachers may have worried about their grades and may have acted differently when teaching the lesson as a consequence of this worry. In a similar way, it was seen in the written statements made that four among five pre-service teachers mentioning that it was unnecessary to give the surface area formula to students stated in face-to-face interviews that the formula should be known but its logic should be made understood.

On the other hand, the written statement of pre-service teacher $T_{1}$, who emphasized that the surface area formula of the cylinder should be shown using the development of the cylinder in his/her written statement but said that it would be appropriate to directly give the formula in the face-to-face interview, is presented in Figure 3.

When Figure 3 was analyzed, it was seen that the pre-service teacher stated that he/she would give the surface area formula to students in a meaningful way by making use of the development of the cylinder. In the one-to-one interview conducted with pre-service teacher $T_{1}$ regarding his/her written statement, he/she was asked whether he/she would use the same way in teaching the surface area formulae of the other geometric objects, and thus an attempt to analyze pre-service teacher's opinions on the surface area formulae in more detail was made. In this regard, the statement of the pre-service teacher is as following.

"Teacher, I will firstly give all surface area formulae to students but I will give the formula based on the development of geometric objects that I can show by their open shapes. If I do not know or have not understood the open shape of the geometric object given, I will directly give the formula. However, students have to use the surface area of the cylinder formula because they will not be able to imagine the development of the cylinder"

When the statements of the pre-service teacher were analyzed, it was seen that he/she could make sense of the concept of the surface area but had concerns regarding the teaching of the surface area formulae because of having a concern regarding the developments of geometric objects. Furthermore, it was observed that the written and verbal statements of the pre-service teacher were in conflict with each other because while he/she stated in his/her written statement that the surface area of the cylinder formula could be easily shown by the development of the cylinder, hence, it was unnecessary to memorize the formula, however, he/she stated in his/her one-to-one interview that students would not be able to imagine the development of the cylinder, hence, they should know the formula by heart. When the observation data of pre-service teacher $T_{1}$ were analyzed to see whether he/she applied these statements during teaching, it was seen that the pre-service teacher directly used the formula as of the very first examples that required finding the surface area and found a solution by heart during teaching. In this regard, the example solved by pre-service teacher $T_{1}$ during teaching and its solution are presented in Figure 4.

Regarding Figure 4, pre-service teachers' statements during the lesson are as following:

"What is the surface area formula? (waits for a while) Let's see, we find it by $2 \pi \mathrm{r}(\mathrm{r}+\mathrm{h})$ formula. We get 36.15 from 2.3.6(6+9) and then we get $540 \mathrm{~cm} 2$ from it."

When the pre-service teacher's statements were analyzed, it was seen that he/she knew the logic of the surface area of the cylinder formula and could show it to students; however, he/she could not give up the logic of memorizing in practice and performed an application by directly using the formula.In other words, when the written statements of the pre-service teacher are examined, he/she expresses that it is a wrong strategy to directly give the formulae, while in the face-to-face interview, he/she mentions that it is necessary to directly give the formula to students when teaching in some cases and even when teaching the surface area formula of the cylinder. It was seen that the pre-service teacher encouraged students to directly use and memorize the formula during teaching.

It was also seen that pre-service teacher $\mathrm{T}_{2}$, who stated that he/she could teach the surface area of the cylinder formula by making use of the development of the cylinder, could not draw the development of the cylinder correctly and hence could not obtain the formula correctly. The written statement made by this pre-service teacher is presented in Figure 5.

When the pre-service teacher's statements were analyzed, it was seen that he/she could make sense of the concept of the surface area but had shortcomings in his/her knowledge of the development of the cylinder. Furthermore, it was seen that the pre-service teacher frequently used the expression of the circumference for the circles in the surface development of the cylinder and made mention of the area of the circumference. Therefore, it can be said that the pre-service teacher had incorrect information on mathematical concepts.

In short, when examining the written statements of pre-service teachers related to teaching the surface area formula of the cylinder, it was seen that all pre-service teachers were on the side of explaining the surface area formula of the cylinder using the development of the cylinder. However, some pre-service teachers made inconsistent statements both in the observation data and with their oral and written statements and said that students should be made to memorize the formula. It was seen that pre-service teachers making such inconsistent explanations provide for justifications of the examination system, education system, time constraints or that the development of three-dimensional objects cannot be imagined. Furthermore, it was seen that some pre-service teachers may have different worries again resulting from the 
development of geometric objects in their explanations regarding the teaching of the formulae of other geometric objects.

Accordingly, it was seen that pre-service teachers would not experience difficulty in the representation of the surface area formula of the geometric object given if they could make the development of that object, but they were on the side of memorizing the formula and making it memorized if they had problems regarding the development of the geometric object given.

Considering all these findings, it can be said that the teaching strategy knowledge of pre-service teachers with regard to teaching the surface area formula of the cylinder is not at the required level, but it is at the sufficient level when compared to the teaching of other geometric formulae.

\subsection{Finding and Interpretation Regarding the Area Formula of the Triangle}

In the interview made with ten pre-service teachers for the purpose of determining the teaching strategy knowledge of pre-service teachers of the area formula in the triangle, while eight pre-service teachers said that they would start from the area formula of the parallelogram in order to explain the area formula of the triangle to students, one pre-service teacher stated that he/she would first make students comprehend the right-angled triangle formula from the area equation of the square, and one pre-service teacher said that he/she would directly give the formula. Furthermore, it was seen that 8 pre-service teachers preferred to present the relation between the parallelogram and triangle visually while making the students confusing the area equations of the triangle and parallelogram recognize their mistakes, one pre-service teacher preferred to make them directly remember the triangle formula, and one pre-service teacher preferred to ensure that the student realized his/her own mistake by giving contrary examples. The explanation of $T_{2}$, among the pre-service teachers who defend that the area equation of the parallelogram can be the starting point in teaching the area equation of the triangle, is presented in Figure 6.

When Figure 6 is examined, it is seen that the pre-service teacher adopts a strategy that makes the student realize his/her own mistake in order to correct the student's mistake in the scenario question. In addition to this, the pre-service teacher stated that he/she would teach starting from the area formula of the parallelogram when teaching the area formula of the triangle to students, and permanence could be increased by using concrete materials during this teaching process. This explanation of the pre-service teacher is a beneficial one in showing the relationship between the triangle and parallelogram and that mathematics is a system of interrelated patterns.

In addition to this written explanation of the pre-service teacher, the face-to-face interview was held with the pre-service teacher in order to make the thoughts about the teaching of the area equation of the triangle clearer and examine it more in-depth. The explanation made by the pre-service teacher in the face-to-face interview regarding the second question is as follows.

"I think the teacher should make the student find the solution by asking questions; I mean; the student should find it. If I were a teacher, I would first ask the area of the parallelogram, then, the area of the triangle. When the student gave the same answer, I would show whether the parallelogram and triangle are similar. Then, the student would naturally understand the difference. I would show that the triangle consists of the parallelogram as well. I would show that we find the area from the parallelogram again. Then, the student would comprehend it better. I anyways use concrete materials; students can understand it better this way. When giving the equation of the area of the triangle, I will be teaching something that they do not know starting from something they know."

Upon examining the explanation of the pre-service teacher, it is seen that he/she emphasizes with his/her written explanation that students should be made to explore their own mistakes by themselves, and the area formula of the parallelogram and concrete materials should be used when teaching the area formula of the triangle. Furthermore, the pre-service teacher was asked how to teach the area equation of the parallelogram during the face-to-face interview in order to understand his/her general point-of-view about the teaching of the formulae. Below is the direct quotation from the statement of the pre-service teacher in regard to this question.

"I directly give that formula since we cannot infer it from anything. I give it as a.b."

Upon examining the statement of the pre-service teacher related to teaching the area formula of the parallelogram, it is seen that he states that he will directly give the formula to students contrary to the strategy he followed in teaching the area formula of the triangle since this formula cannot be obtained from anywhere. In this context, it is understood that the pre-service teacher does not know the logic of the area formula of the parallelogram starting from the statement made. Thus, it can be said that the pre-service teacher is not on the side of making the formula be memorized when teaching the formulae to which he/she can give a meaning but makes students directly memorize the formulae to which he/she cannot give a meaning.

The observation data of the pre-service teacher were examined in order to see the extent to which the pre-service teacher uses the written and oral statements with regard to the teaching of the area formula of the triangle when teaching and to obtain more in-depth information. The observation data of this pre-service teacher are given in Figure 7.

Upon examining the observation data of the pre-service teacher, it was seen that concrete materials and the area formula of the parallelogram were used when teaching the 
area formula of the triangle as stated in the written and oral explanations on the teaching of the area formula of the triangle. However, it was observed that the pre-service teacher could not effectively use this material he/she prepared in order to associate the area formula of the triangle and the area formula of the parallelogram neither with the guiding questions nor in terms of drawing attention. Furthermore, it was observed that the examples solved by the pre-service teacher during the lesson were not suitable for the objective, and the pre-service teacher followed a path from abstract to concrete by first giving the formula and then using materials in the observation data of the pre-service teacher. In other words, it was seen that the pre-service teacher failed to effectively apply in practice the statements made in theory.

On the other hand, the statement of pre-service teacher $\mathrm{T}_{7}$ who prefers to directly give the formula in the explanations on the area equation in the triangle is presented in Figure 8.

When the written statement of the pre-service teacher was examined, it was seen that he/she stated that he/she would say the area formula of the triangle when correcting the student's mistake mentioned in the scenario question, he/she emphasized what the concept is in the teaching of the formula of the area of the triangle rather than the logic behind the formula, and he/she was on the side of directly giving the formula. Starting from these statements of the pre-service teacher, it can be said that there are important shortcomings in his/her content knowledge and consequently, his/her strategy knowledge is weak. Furthermore, this statement of the pre-service teacher guides students towards memorizing the formula and is a superficial explanation in terms of teaching the formula.

The face-to-face interview was held with the pre-service teacher in order to examine this statement made superficially by the pre-service teacher in a more detailed way. The direct quotation of the statement made by the pre-service teacher on the area formula of the triangle and the area formula of the parallelogram in the face-to-face interview is as follows.

"Here, the student told the area formula of the triangle incorrectly. I think we can start from the area of the parallelogram. I would say that we can obtain the area of the triangle by dividing the parallelogram into half. I directly give the formula of the parallelogram when teaching it because I do not exactly remember how this formula is obtained. I guess we were using the rectangle. I do not remember now."

When the statements of the pre-service teacher were examined, it was seen in the written statement that he/she had to give the area formula of the triangle directly as the area formula of the triangle cannot be obtained by using the parallelogram when correcting the student's mistake, but in the face-to-face interview, it was seen that he/she would teach the area formula of the triangle starting from the equation of the area of the parallelogram. Here, it is seen that the knowledge of the pre-service teacher about the relationship between the area formula of the triangle and the area formula of the parallelogram is not clear and he/she is in a dilemma.

Consequently, it can be said that the pre-service teacher failed to fully understand the relationship between the area formula of the triangle and the area formula of the parallelogram. Furthermore, it was seen that the pre-service teacher stated that he/she would give the formula directly to students since he/she did not know how to obtain the area formula of the parallelogram. In this context, it can be said that the reason for the pre-service teacher's making such an explanation on the teaching of the area formula of the parallelogram results from the shortcomings in the content knowledge.

When the written and oral statements of the pre-service teachers on the area formula of the triangle were examined, it was seen that the pre-service teachers (9) stated that it would be suitable to teach the area equation in the triangle by mostly benefiting from the area equation of the parallelogram and to reinforce this by using materials. However, it was seen that neither of the two pre-service teachers observed while teaching could effectively use these strategies that they adopted in their written and oral explanations. In other words, it was seen that these pre-service teachers had a problem in implementing what they said although they could orally express what to teach and how to teach the area equation in the triangle. Furthermore, it was seen that the pre-service teachers were able to correctly associate the area formula of the triangle and parallelogram while their explanations on the teaching of the area formula of the parallelogram that developed during the oral interview remained insufficient. In this context, it was observed that 6 pre-service teachers tended to directly give the formula without making any instructional explanation in contrast with the strategy they defended in teaching the area formula of the triangle.

On the other hand, it was seen that there was a pre-service teacher who failed to make clear explanations on the logic of the area formula of the triangle and adopted a memorization strategy.

\subsection{Finding and Interpretation Regarding the Linear Equation the Graph of Which Is Given}

In the interview held with 10 pre-service teachers for the 3rd question prepared in order to determine the teaching strategy knowledge with regard to the formula used for finding the linear equation the graph of which is given, it was seen that eight pre-service teachers tended to directly give the formula without making any explanation on the logical justification underlying the formula. It was also seen that two pre-service teachers said that they would show how to obtain the formula, but it was still important to know this formula. The explanation of pre-service teacher $T_{8}$ with regard to this is presented in Figure 9. 


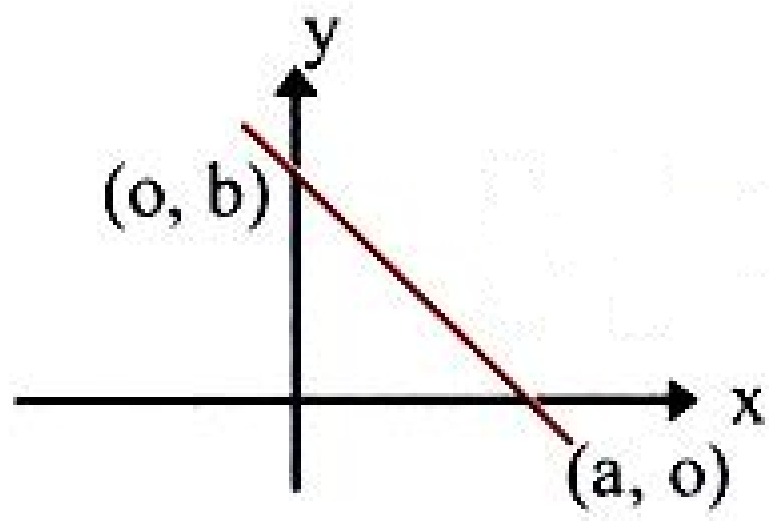

Teacher Pinar gave the following formula to her students to find the equation of a line the graph of which is given on the side.

Teacher Pınar made the following statement regarding this formula:

"If you do not know this formula by heart you cannot find the equation of a line the graph of which is given in this way, therefore, all of you have to memorize this formula."

Do you agree with this statement of teacher Pinar? Write in detail whether you agree with the justification.

I don't agree. Instead, the equation is when we say that the equation will be in the form of $\mathrm{kx}$, and for $\mathrm{x}=\mathrm{a}, \mathrm{y}=0$, and for $\mathrm{x}=0, \mathrm{y}=\mathrm{b}$ that will help them read the graph.

The formula can be given after showing and applying this in questions. The students are told that they can use whichever they find easier. So, each student does not necessarily have to know this.

Upon examining Figure 9, it is seen that the pre-service teacher states that the equation of a line, the graph of which is given, can be found without knowing the formula, and students should be set free as to whether to use the formula or not. Upon examining the oral statement of the pre-service teacher, that he/she can easily extract the formula given from such a general linear equation as $y=a x+b$ and states that he/she will follow such a path in the teaching of this formula can be shown as a clear and understandable method for students.

The statement of the pre-service teacher made in the face-to-face interview held in order to examine his/her opinions in the written statements in a more detailed way is as follows:

"Sir, even I do not know the formula. But, if I am given such a coordinate and asked to find the equation, I find it as I write it. So, I start from the fact that the linear equation is $\mathrm{ax}+\mathrm{by}+\mathrm{c}=0$ as I know this. I mean, I solve the equation by putting the points given in the coordinates in their places. As I say, I also do not know this formula; I solve such problems as I have mentioned. But I still give this formula to students. I first teach students how to read the coordinate because this is important in forming an equation. I mean, I make students understand that $\mathrm{y}$ will be zero when we put a in the place of $x$, or $x$ will be zero when we put $b$ in the place of $y$. Then, I find it from the linear equation. Then, I do this in some similar examples, so as to ensure permanent learning. But, I still give the formula because I give students any option as each student is different, and set them free in choosing which one to use."

When the statement made by the pre-service teacher during the face-to-face interview is examined, it is seen that he/she also does not know this formula by heart and it is not necessary to use the formula when finding a linear equation the graph of which is given. Despite this statement of the pre-service teacher, he/she stated that the formula should be still given as a result of individual differences among students, but the logic of the formula must be definitely explained. In this context, it can be said that the pre-service teacher thinks that there is no need to memorize the formula given and attributes more importance to meaningful learning related to the teaching of this formula rather than learning by heart. It was also seen that the pre-service teacher attributed importance to key concepts such as placing the points in the coordinate system and being able to interpret the coordinate system when teaching how to establish a linear equation and made instructional explanations with regard to these. In contrast with pre-service teacher $\mathrm{T}_{8}$, the written statement of $\mathrm{T}_{3}$ among 8 pre-service teachers, who defended that it is hard to solve the problems on finding the linear equation the graph of which is given without knowing the formula and thus expressed that students should be made to memorize the formula, is shown in Figure 10.

Upon examining the statement of the pre-service teacher, it was seen that it was long and hard to show how to obtain this formula, and thus he/she would directly give the formula to students without making any comment on the logic of the formula. Considering this explanation, it seems hard to understand whether the pre-service teacher has any idea as to how to obtain the formula. Thus, the face-to-face interview was held with the pre-service teacher in order to be able to examine the thoughts of the pre-service teacher on the logic and teaching of the formula given in a more detailed way. The direct quotation from the statement made by the pre-service teacher in the face-to-face interview is presented below.

"I really do not know how to infer this formula. I mean, I tried a bit during the written explanation, but I failed. That's why I guess I directly give the formula. I mean, I guess I can find it from the slope, etc., but such an explanation will not be suitable for a child at that age."

In the face-to-face interview held with pre-service teacher $\mathrm{T}_{3}$, it was seen that he/she mentioned in his/her written statement that this formula could be found by using the slope, but in the face-to-face interview, it was seen that he/she actually did not have any idea about the inference and logic of the formula. In this context, the pre-service 
teacher stated that students should be made to memorize the formula, and explained the justification for this as it would be more appropriate to directly give the formula since he/she did not know how to obtain it and the logic of this formula. Upon examining the statements of the pre-service teacher, it can be said that he/she adopts a strategy that includes the logic of memorization in the teaching of the formula given, and thus, in case students forget this formula, there will be no alternative way to form the linear equation the graph of which is given. The observation was made to see how the pre-service teacher applied his/her statements related to the teaching of the formula given during the lesson in a more detailed way. The observation data of this pre-service teacher are presented in Figure 11.

Upon examining Figure 11, it is seen that the pre-service teacher directly gives the formula that requires finding the linear equation the graph of which is given to students and makes no instructional explanations on the logic of the formula or how it is obtained. It was also observed that the pre-service teacher emphasized during the lesson that this formula must be known in order to be able to find the equation of a line, the graph of which is given. In other words, the pre-service teacher stated that students should memorize the formula. Nevertheless, this approach may lead to considering mathematics as a mass of meaningless rules, and consequently, the development of a negative prejudice against mathematics.

In a similar way, $\mathrm{T}_{6}$ among the pre-service teachers who defended that the formula must be memorized stated that the formula could be obtained but this would lead to time loss for students. The written statement of this pre-service teacher is presented in Figure 12.

a) Sena, you do not need to memorize this formula. You do not need to memorize if you completely understand the development of the right circular cylinder.

b) I would firstly make her understand the surface area via development. Now let's perform the development of the right circular cylinder.

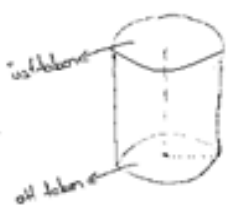

As you can see, this is a right circular cylinder. A circle comes into view when you carefully look at the upper base and also the lower base, and a shape like

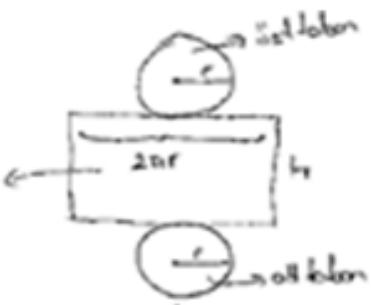

comes into view when we open the shape.

Now let's look which geometric object is the lateral area? Is not it a rectangle? So, what is the area formula of therectangle? Is it the multiplication of two intersecting vertical edges. Then the lateral area is $2 \Pi \mathrm{rh}$. The upper base and lower base are circles. The area of the circle is $\Pi r^{2}$. Then, would not the whole area be $2 \Pi r h+\Pi r^{2}$ ? Let's clear up, we have achieved $2 \Pi r(r+h)$ formula. You do not need to memorize. We do not memorize the formula as it is very simple.

a) Sena, you do not need to memorize this formula. You do not need to memorize it if you completely understand the development of the right circular cylinder.

b) I would firstly make her understand the surface area from the development. Now let's perform the development of the right circular cylinder.

As you can see, this is a right circular cylinder. A circle comes into view when you carefully look at the upper base and also at the lower base, and a shape like ...comes into view when we open the shape.

Now let's look which geometric object is the lateral area? It is a rectangle, isn't it? So, what is the area formula of the rectangle? Is it the multiplication of two intersecting vertical edges. Then, the lateral area is 2pirh. The upper base and lower base are circles. The area of the circle is pir ${ }^{2}$. Then, will not the whole area be 2 pirh + pir2? Let's reorganize it, we have obtained 2 pir $(\mathrm{r}+\mathrm{h})$ formula. You do not need to memorize it. We do not memorize the formula as it is very simple.

Figure 3. Pre-service teacher $T_{1}$ 's written statement regarding the surface area of the cylinder formula 


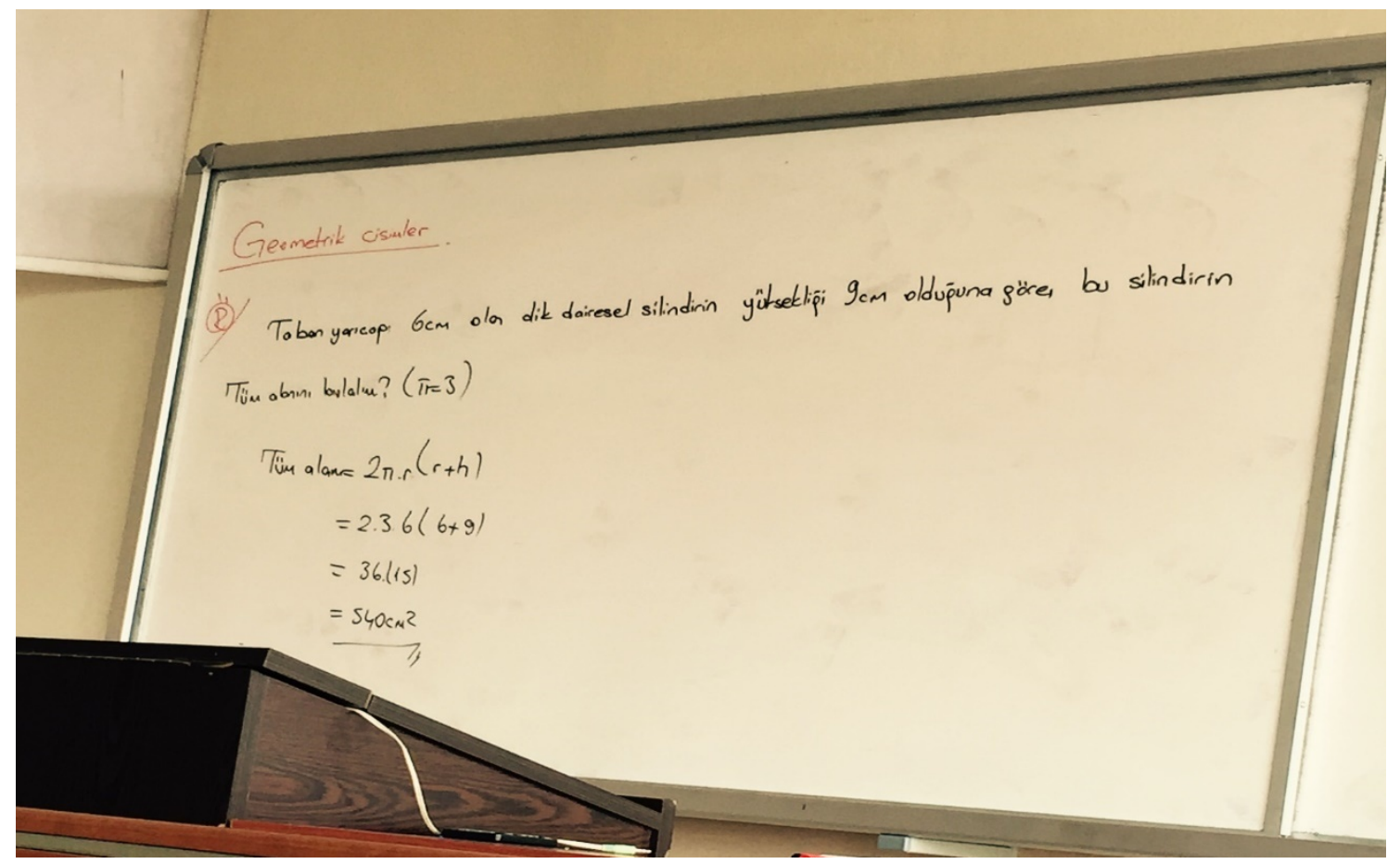

(Translate: The height of a right circular cylinder, the base radius of which is $6 \mathrm{~cm}$, is $9 \mathrm{~cm}$, find the whole area of this cylinder.)

Figure 4. Pre-service teacher $T_{1}$ 's solution to the example that required finding the surface area of the cylinder

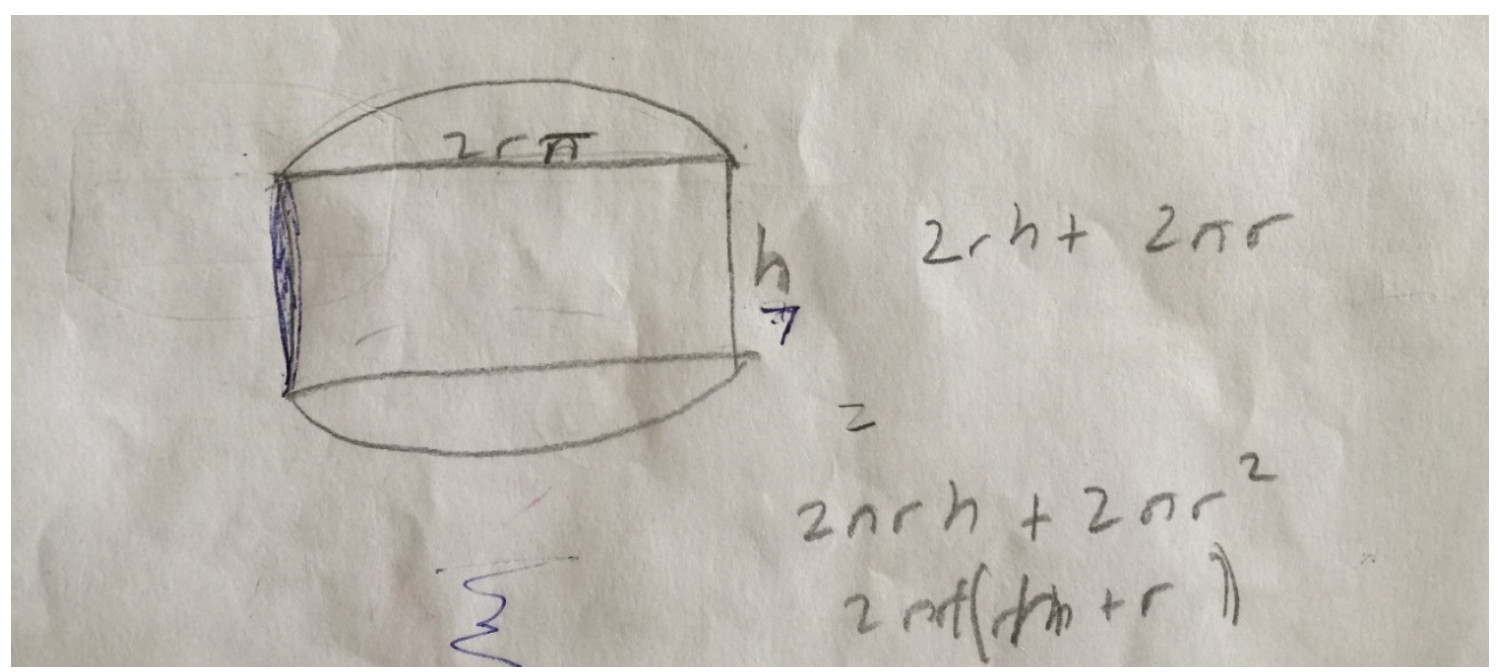

Figure 5. Pre-service teacher $\mathrm{T}_{2}$ 's statement regarding the development of the cylinder 
Teacher Selin wrote a question for finding the area of a triangle on the blackboard, and the following dialogue took place with her student Ali.

Teacher : Ali, tell us how do we find the area of a triangle?

Ali: Teacher, we multiply the base length by height.

Teacher: Ok, what would we do later on?

Ali: that's all teacher, no more

Teacher: The formula that you have said seems like the formula of the parallel edge, we multiply the base length by height and then divide it by two while finding the area of the triangle, don't we?

a) According to you, did teacher Selin act properly? If you were teacher Selin, how would you correct Ali's mistake?

b) If you were teacher Selin, what type of path would you follow while teaching the area relation in the triangle?

a) It is not. For, we should correct the student's mistake by making him/her find it, not by telling it. I would ask Ali how we find the area. I would help him remember. Then, I would show the student that parallelogram consists of two triangles. I would make him comprehend that the area of the triangle is equal to the half of the area of the parallelogram if parallelogram consists of two triangles.

b) It will be more lasting and educative to use materials and present them to students visually. I would prepare two materials as parallelogram and rectangle. For example, a paper material. He/she will see that two triangles are formed when folding it in half, and comprehend that the area of the triangle is half the area of the parallelogram.

Teacher Selin wrote a question for finding the area of a triangle on the blackboard, and the following dialogue took place with her student Ali. Teacher: Ali, tell us how do we find the area of a triangle?

Ali: Teacher, we multiply the base length by height.

Teacher: Ok, what would we do later on?

Ali: that's all teachers, nothing more

Teacher: The formula that you have mentioned seems like the formula of the area of the parallelogram, we multiply the base length by height and then divide it by two while finding the area of the triangle, don't we?

a) In your opinion, did teacher Selin act properly? If you were teacher Selin, how would you correct Ali's mistake?

b) If you were teacher Selin, what type of path would you follow while teaching the area equation in the triangle?

a) No, she didn't because we should correct the student's mistake by making him/her find it, not by telling it. I would ask Ali how we find the area of the parallelogram. I would help him recall it. Then, I would show the student that parallelogram consists of two triangles. I would make him comprehend that the area of the triangle is equal to the half of the area of the parallelogram if parallelogram consists of two triangles.

b) It will be more lasting and educative to use materials and present them to students visually. I would prepare two materials in the form of a parallelogram and rectangle. For example, a material from paper. He/she will see that two triangles are formed when I fold it in half and comprehend that the area of the triangle is half the area of the parallelogram.

Figure 6. Pre-service teacher $T_{2}$ 's written statement regarding the area formula of the triangle 


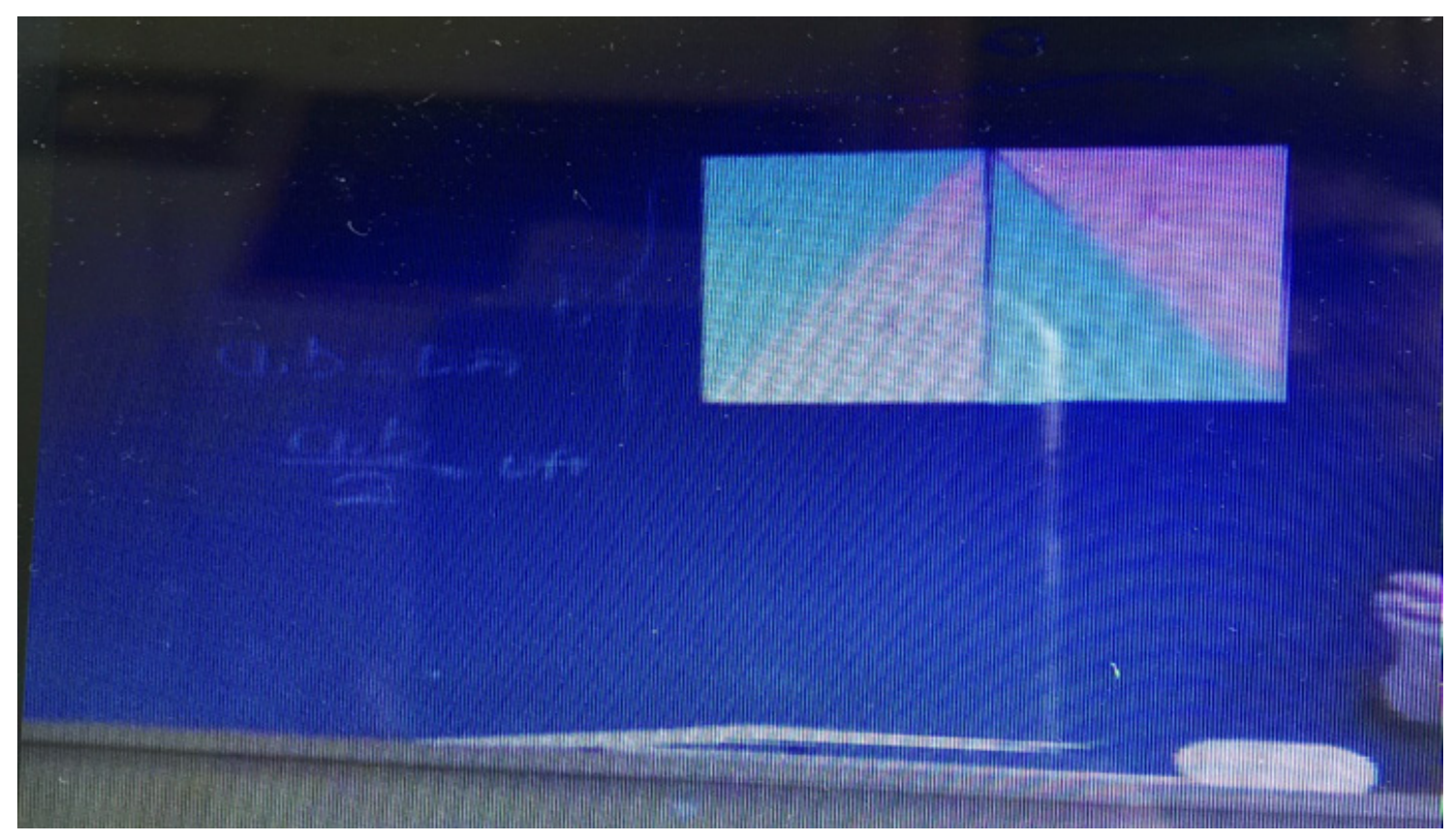

Figure 7. The observation data regarding the area formula of the triangle of pre-service teacher $T_{2}$

a) We can make use of the triangle when finding the area of the parallelogram. However, we cannot use parallelogram when finding the area of the triangle. I would say the area formula of the triangle.

b) I would cut papers in triangles and bring them to school. I would also bring a hollow triangle. I would say that the first figure has an area while the second one does not. I would say that we should find the region limited while finding the area. I would say that this shape will have a height. I would then give the area formula.

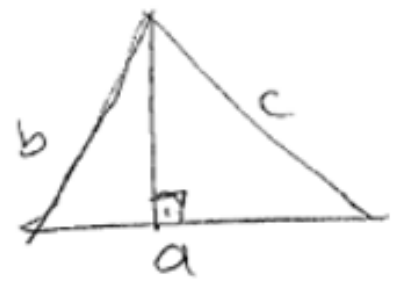

\section{$\frac{\text { Base Area } \times \text { Height }}{2}$}

a) We can make use of the triangle when finding the area of the parallelogram. However, we cannot use the parallelogram when finding the area of the triangle. I would say the area formula of the triangle.

b) I would cut paper in triangles and bring them to school. I would also bring a hollow triangle. I would say that the first figure has an area while the second one does not. I would say that we should find the region limited by it while finding the area. I would say that this shape has a height. I would then give the area formula.

Figure 8. Pre-service teacher $T_{7}$ 's written statement regarding the area formula of the triangle 


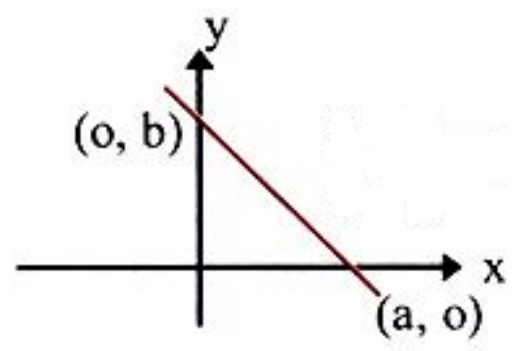

Teacher PInar gave her students the following formula to find the equation of a line the graphic of which is given on the side.

$$
\frac{x}{a}+\frac{y}{b}=1
$$

Teacher Pınar made the following statement regarding this formula;

"If you do not know this formula by heart you cannot find the equation of a line the graphic of which is given in this way, therefore all of you have to memorize this formula."

Do you agree with this statement of teacher PInar? Write in detail whether you agree with the justification.

I don't agree. Instead, the equation is when we say that the equation will be in the form of $y=k x+t$, and for $\mathrm{x}=\mathrm{a}, \mathrm{y}=0$, and for $\mathrm{x}=0, \mathrm{y}=\mathrm{b}$ that will help them read the graph.

$$
\begin{aligned}
& \Rightarrow \quad \begin{array}{l}
k \cdot a+t=0 \\
k, 0+t=b, t, b
\end{array} \quad \begin{array}{l}
k \cdot a+b=0 \\
k=-\frac{b}{a}
\end{array}
\end{aligned}
$$

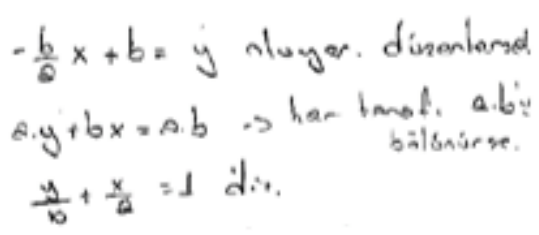

The formula can be given after showing these. The students are told that they can use whichever they find easier. So, each student does not necessarily have to know this.

Figure 9. Pre-service teacher $T_{8}$ 's written statement regarding the linear equation the graph of which is given

$$
\begin{aligned}
& \text { Bence formblion bilinmesi ferekyor cenki formin bi citure } \\
& \text { bituck rein. egin bitinmeli ve tostigi noctalarde cenclemi }
\end{aligned}
$$

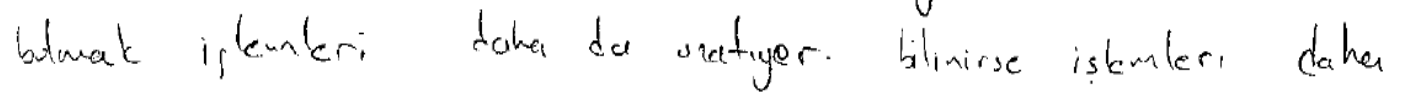

$$
\begin{aligned}
& \text { da kisaltins olor }
\end{aligned}
$$

(Translate; I think the formula must be known since the slope must be known in order to infer the formula, and finding the equation at the points that it cuts off makes the process longer. The processes take shorter time if the formula is known.)

Figure 10. Pre-service teacher $T_{3}$ 's written statement regarding the linear equation the graph of which is given 


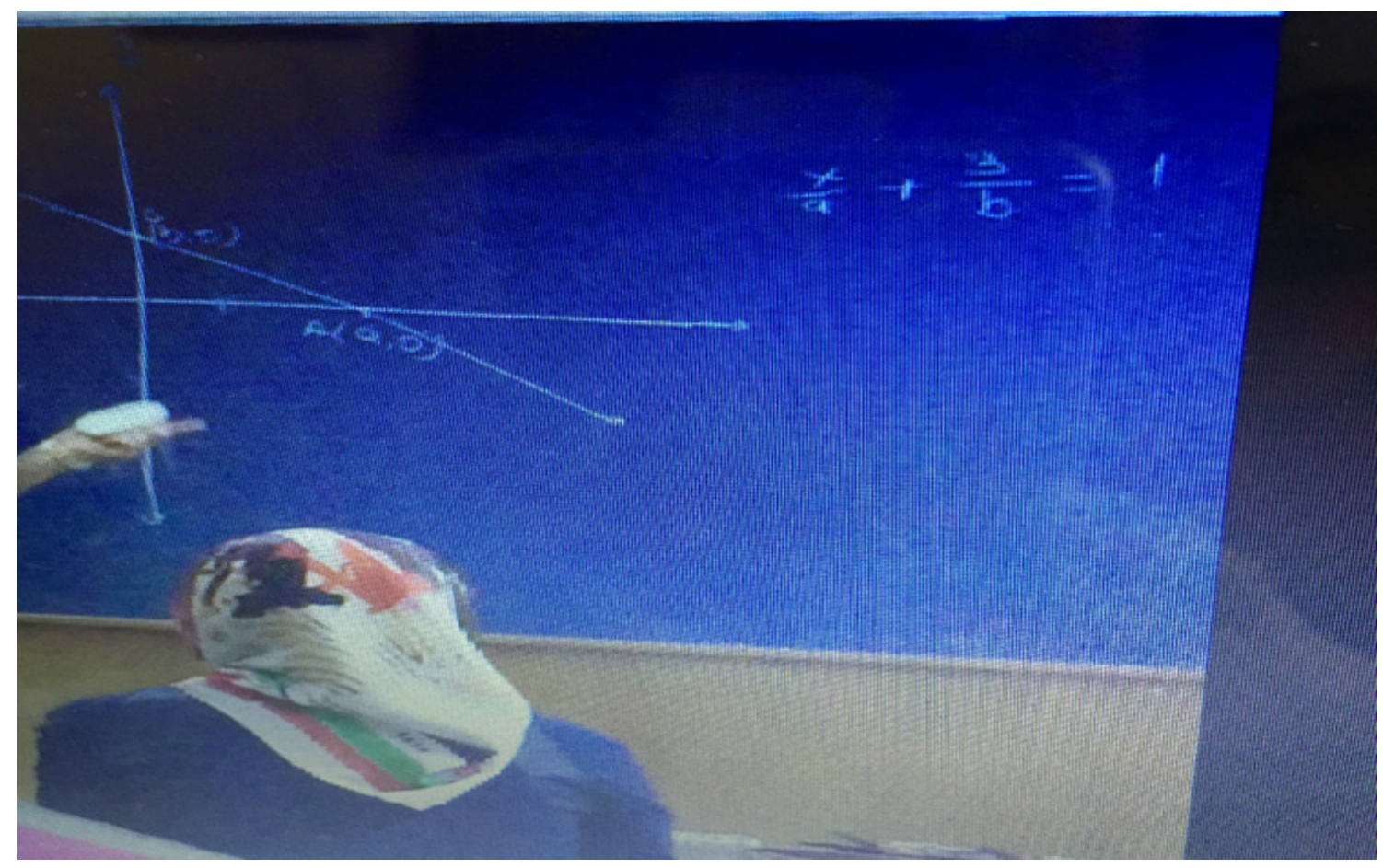

Figure 11. The observation data of pre-service teacher $T_{3}$ regarding the linear equation the graph of which is given

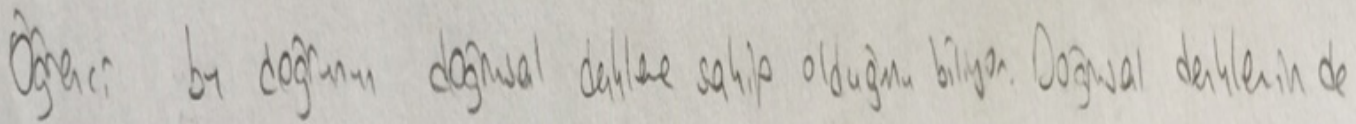

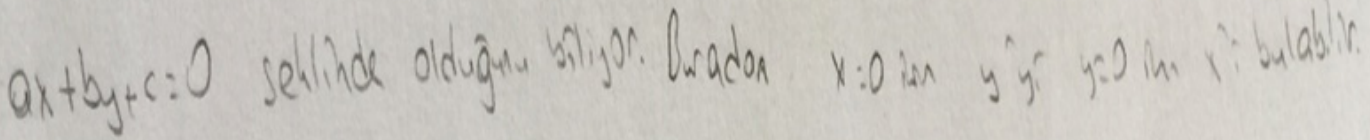

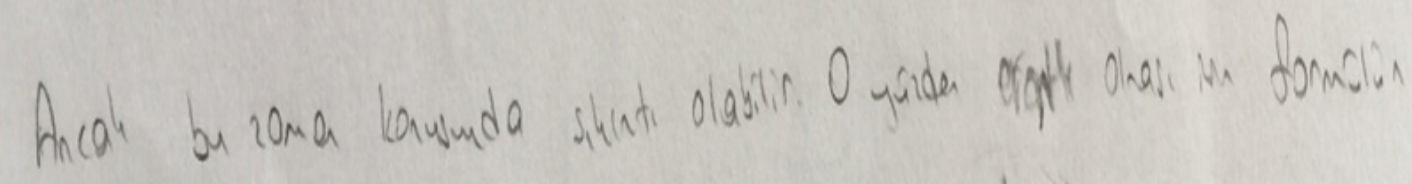
bilines gentyor.

Figure 12. Pre-service teacher $T_{6}$ 's written statement regarding the linear equation the graph of which is given 
Upon examining Figure 12, it is seen that the pre-service teacher states that a linear equation the graph of which is given can be found by using the equation $a x+b y+c=0$, but it will be more suitable to know the formula for practicality. Furthermore, it is seen that the pre-service teacher says that direct giving this formula to students that is interpreted as finding the $y$ value for $x=0$ and $x$ value for $y=0$ will be more suitable for the students' level. In this context, it can be said that it is quite interesting that the pre-service teacher defends that students must be made to memorize the formula although he/she can give meaning to the formula in question.

The statement of the pre-service teacher in the face-to-face interview held with the pre-service teacher in order to understand and investigate these strategies adopted by the pre-service teacher in the written statement in a more detailed way is as follows.

"Well, I don't defend that all mathematical formulae should be memorized because I myself do not know most formulae by heart, especially trigonometry. I would give this formula to students. However, my motive is their time constraint as they are preparing for the exam. For, we will already teach students how to place these points anyways. The student can find $\mathrm{y}$ by giving 0 to $\mathrm{x}$, and $\mathrm{x}$ by giving zero to $\mathrm{y}$; the student can infer this somehow, but it will take a lot of time. We obtain the linear equation if we multiply both parts with $\mathrm{ab}$ after giving the formula, but I cannot say something for sure as I don't know whether students understand this. I would give the formula directly, and then ensure that the formula is well understood by giving examples."

Upon examining the explanations of the pre-service teacher, it was seen that he/she explained the reason for his/her justification for thinking that the formula should be made memorized despite giving meaning to the formula is that it is beneficial in terms of saving time for students during the exams. Nevertheless, from this point of view, there are tens of formulae that students must memorize for each subject and it is almost impossible for them to keep all of these formulae in their minds. At this point, it can be said that the pre-service teacher does not take into consideration the possibilities that the formulae that are made memorized in the teaching of the subjects are not remembered or are misremembered.

Furthermore, upon examining the observation data made in order to be able to determine how the pre-service teacher applied the explanations he/she made while teaching, it was seen that the pre-service teacher did not have good command of mathematical concepts and tended to directly give definitions and formulae as specified in his/her written and oral statements.

In short, upon examining the statements of the pre-service teachers on the teaching of the formulae related to the linear equation the graph of which is given, it was seen that most (8) of the pre-service teachers were on the side of directly giving the formula to students. In this sense, when the written, oral and observation data of the pre-service teachers were examined, it was seen that the reason for their adopting such a teaching strategy resulted from their lack of content knowledge about finding an equation the graph of which is given. On the other hand, it was seen that there were 2 pre-service teachers who thought that the logic of the formula must be definitely shown to students when teaching it. Furthermore, it was seen that almost all of the pre-service teachers emphasized that students must know and use the formula because of the examination system in our country. Considering all these findings, it can be said that the strategy knowledge of the pre-service teachers regarding the teaching of the formula used in order to find the linear equation the graph of which is given is quite insufficient.

\section{Conclusions, Discussion, and Suggestions}

It was seen that all of the pre-service teachers used the exploratory teaching strategy regarding the teaching of the surface area formula of the cylinder and defended that it would be beneficial for students to establish the formula together with students using the question and answer technique. It was seen that the pre-service teachers who preferred to teach in this way said that students would learn a formula that they obtained themselves more meaningfully and they would not have to memorize the formula. Furthermore, it was seen that the pre-service teachers emphasized that concrete materials should be used when teaching this formula to students and that thus the surface area formula of a three-dimensional object, which is an abstract concept, can be comprehended better. Similar to with this result in reference [13], it was emphasized that necessary knowledge related to what these concepts were and how they were gained instead of memorizing of surface area by pre-service teachers With regard to the surface area formulae of geometric objects in general, it was found out that the pre-service teachers generally tended to benefit from the development of a particular object while teaching its surface area formula if they could draw the development of a given geometric object, but they were on the side of directly giving the formula if they did not know the development. Furthermore, it was seen that the pre-service teachers emphasized that it was quite important to teach what the concept of the surface area was in teaching the surface area formulae, and students who learned the concept of the surface area meaningfully would not have any problem in giving meaning to the surface area formulae. In this context, the pre-service teachers emphasized that they could find the surface area of the cylinder by using the development of the cylinder without the need for students who have fully understood the concept of the surface area to memorize the formula. It was seen that one of the pre-service teachers, who made such an explanation and was observed while teaching, did not use the formula in any 
way while making example solutions that required finding the surface area of the cylinder and taught by using the development of the cylinder. In other words, it was seen that this pre-service teacher applied exactly the same of what he/she stated in his/her written statements and face-to-face interviews while teaching. However, it was seen that other pre-service teachers who were observed failed to effectively apply what they stated in the written statements and oral interviews while teaching. In studies carried out on pre-service teachers' teaching strategy knowledge, it was observed that pre-service teachers' statements regarding the question of "How would you teach?" and their in-class practices were not always consistent with each other [16].

Besides, though pre-service teachers' instructive explanations, they couldn't teach surface area formulas of general geometric shapes effectively. In this concept, it was seen that if pre-service teachers could draw the development of the geometric shape, they would benefit the development while teaching it or if they didn't know the development, they tend to give the formula directly.

In other words, it was observed that the pre-service teachers failed to implement in practice the teaching strategies they expressed in theory, and they tended to make students memorize the formula at the point when their content knowledge was inadequate.

In addition to all these, it was also determined that the pre-service teacher, who stated that he/she would use the development of the cylinder while teaching the surface area formula of the cylinder, failed to correctly draw the development of the cylinder and thus became unsuccessful in making the inference of the formula. This is something thought-provoking for a pre-service teacher in the last grade since a pre-service teacher in the last year of the department of primary school mathematics teaching will start to teach at schools soon, having completed all major area courses and education courses. That a pre-service teacher who has come to this stage fails to draw the development of the cylinder and find its surface area formula is worrisome. This result is in parallel to the result found by Reference [31], that pre-service teachers generally have problems in drawing the development of geometric objects while drawing three-dimensional geometric objects, and they only draw the most frequently used developments of three-dimensional geometric objects.

It was seen that while pre-service teachers teach the area formula of the triangle to students, 8 pre-service teachers use the area formula of the parallelogram, and they prefer finding the solution together with students using the question and answer technique. Furthermore, it was also seen that pre-service teachers adopting teaching in this way aim to draw attention to the relationship between the area equations of the parallelogram and triangle by using concrete materials, and they are on the side of teaching the formula upon this relationship to students. It was seen that they couldn't practice these explanations though these 8 pre-service teachers' instructive explanations related to the teaching of the given formula. In this context, one of the pre-service teachers observed failed to effectively use the concrete materials he/she prepared and taught from abstract to concrete. In other words, he/she first gave the formula and then used the concrete materials. Again, in the second option of the same question, the pre-service teachers were asked for the paths they would follow in order to make the students confusing the area equations of the triangle and parallelogram realize their mistakes, and most of the pre-service teachers (9) stated that they would prefer to present the relationship between the parallelogram and triangle visually. One pre-service teacher stated that students who confuse the formulae of the parallelogram and triangle should be made to directly remember the formulae in order to make them realize their mistakes. In other words, this pre-service teacher guided students towards memorizing the formula again in order for the student to realize one's mistake and taking precautions in order for the mistake not to be repeated. This result is parallel to the result found by Reference [6,26],

This approach adopted by this pre-service teacher is not correct in terms of mathematics teaching since such an approach limits the possibility of students to think about geometric relations extensively. In this context, it was stated in the literature that rather than formula-based calculations regarding the concepts of the area and volume, experiences such as the virtual covering of the areas allow students to learn more permanently and meaningfully [9].

In this context, when the pre-service teachers who were on the side of teaching the area formula of the triangle meaningfully (9) were asked questions about the teaching of the area formula of the parallelogram during the face-to-face interview, it was seen that 6 pre-service teachers did not know the logic of the area formula of the parallelogram, and thus, they could not make instructional explanations and tended to make students directly memorize the formula.

In short, it can be said that the level of teaching strategy knowledge of the pre-service teachers of the area equation in the triangle is not at the required level. Clearly speaking, it was observed that the pre-service teachers mostly knew the explanation of the area formula in the triangle well, but had problems in applying or teaching this. Although it is a prerequisite of teaching for a teacher to know a field or a subject very well, it is not sufficient for a successful education [11]. For this reason, beyond having a good command of their own field, teachers should have knowledge of how to teach their lesson, how to transmit it to students and get to the level of students [12].

In this concept, in reference [4], it was stated that the teachers tend to teach by the help of traditional methods while they were teaching formulas related to the area measurement.

Most pre-service teachers stated that it is necessary to make students memorize the formula directly without 
giving the logical justification underlying the formula when teaching the formula that requires finding the linear equation, the graph of which is given. Most of the pre-service teachers thinking that students should be made to memorize the formula mentioned that they did not know how the formula was obtained or giving the logic of the formula would not fit the level of students. In addition to this, it was seen that there were 2 pre-service teachers who correctly expressed the logical justification of the formula and made the inference of the formula. These pre-service teachers are of the same opinion that this formula must be definitely given to students, on condition that its logic is shown to students. In other words, the pre-service teachers did not make much explanation on the meaning of this formula and generally made superficial explanations by emphasizing that students should be made to memorize the formula. It was seen that this resulted from the short comings in the content knowledge of the pre-service teachers. Therefore, it was observed that the pre-service teachers who were observed gave the formula directly to students while teaching the subject and made no explanation on the inference of the formula. The reason for this is clear: nobody can teach something that he/she does not know, thus, pre-service mathematics teachers should know mathematics at the level that allows them to teach it [10].With regard to this, in reference [23] was expressed that pre-service teachers fail to meaningfully learn the relation between the rules and concepts given in mathematics, they memorize and thus, they tend to teach by memorization. Furthermore, some of the pre-service teachers defended that the formula given should be memorized by giving such reasons as it is advantageous to know formulae as the examination system requires practicality.

Whereas, in reference [23] it has been stated, the fact that mathematics is a structure involving interrelated concepts and how the rules are constructed and why the rules are used to have to be taught by teachers.

As a result of the study, it was seen that the teaching strategy knowledge of the pre-service teachers about the surface area of the cylinder and the area equation in the triangle is better when compared to the formula of finding the linear equation the graph of which is given. However, it was observed that they failed to effectively apply the teaching strategy knowledge they expressed orally during teaching the subject. In other words, it was observed that they failed to implement in practice the teaching strategy knowledge they had in theory, and hence the teaching strategy knowledge of the pre-service teachers on the geometric formulae given was insufficient.

In the study carried out, it was observed that the pre-service teachers failed to effectively implement in their lessons what they expressed in their written and oral statements, and thus, their level of teaching strategy knowledge was not at the sufficient level. In this context, pre-service teachers should be given the opportunity to perform more applications in Teaching Principles and
Methods, Special Teaching Methods I-II, and Mathematics Teaching Seminar courses. In addition to this, it can be ensured that pre-service teachers think about geometric relations more extensively by including them more into activities during which they will not directly use the formulae during their undergraduate education. Furthermore, pre-service teachers may be raised as more conscious and equipped teachers and transmit what they have learned to their students if they are taught considering the conceptual bases of mathematical concepts both in their education courses and field courses in their university education.

\section{REFERENCES}

[1] Craine, T. V. \& Rubenstein, R. N. (1993). A quadrilateral hierarchy to facilitate learning in geometry. The Mathematics Teacher, 86(1), 30-36.

[2] Barrantes, M., \& Blanco, L. J. (2006). A study of prospective primary teachers' conceptions of teaching and learning school geometry. Journal of Mathematics Teacher Education, 9(5), 411-436.

[3] Jarrah, A.M. (2013). Investigation of jordanian pre-service teachers' beliefs about learning and teaching of mathematics. Unpublished doctoral dissertation, University of Missouri, Kansas City.

[4] Huang, H. M. E. \& Witz, K. G. (2011). Developing children's conceptual understanding of area measurement: A curriculum and teaching experiment. Learning and instruction, 21(1), 1-13

[5] Tan Şişman, G. \& Aksu, M. (2009). Seventh grade students' success on the topics of area and perimeter. Elementary Education Online, 8(1), 243-253.

[6] Toluk Uçar, Z. (2011). Pre-service teachers' pedagogical content knowledge: instructional explanation. Turkish Journal of Computer and Mathematics Education, 2(2), 87-102.

[7] Dağl1, H. (2010). Misconceptions of elementary school students in 5th grades about the perimeter, area and volume concepts (Unpublished master's thesis). University of Kocatepe, Afyon.

[8] Kordaki, M. \& Balomenou, A. (2006). Challenging students to view the concept of area in triangles in a broad context: Exploiting the features of Cabri-II. International Journal of Computers for Mathematical Learning, 11(1), 99-135.

[9] Olkun, S., Çelebi, Ö., Fidan, E., Engin, Ö. \&Gökgün, C. (2014). The meaning of unit square and area formula for turkish students. Hacettepe University Journal of Education, 29(1), 180-195.

[10] Philipp, R. A., Thanheiser, E. \& Clement, L. (2002). The role of a children's mathematical thinking experience in the preparation of prospective elementary school teachers. International Journal of Educational Research, 37(2), 195-210.

[11] Ball, D. L., Thames, M.H., \& Phelps, G.(2008). Content knowledge for teaching: What makes it special? Journal of 
Teacher Education, 59(5), 389-407.

[12] Batur, Z., \& Balc1, S. (2013). Research on turkish pre-service teachers'pedagogical content knowledge. Journal of Adryaman University social sciences institute, 11, 1308-9196.

[13] Gökkurt, B., Şahin, Ö. \& Soylu Y. (2013). An analysis on the relationship between the pedagogical and mathematical content knowledge of mathematics teachers. The Journal of Academic Social Science Studies, 5(8), 997-1012.

[14] Carpenter, T., Fennema, E., Peterson, P., \& Chiang, C., Loef, M., (1989). Using knowledge of children's mathematics thinking in classroom teaching: an experimental study. American Educational Journal, 26, 499-531.

[15] Fennema, E., \& Franke, M. L. (1992). Teachers' knowledge and its impact. In D. A. Grouws (Eds.), Handbook of research on mathematics teaching and learning. New York: Macmillian.

[16] Gökkurt, B., Koçak, M., \&Soylu, Y. (2014, September). Investigation on fractions of prospective teachers' content knowledge and teaching strategies knowledge on. 11th National Science and Mathematics Education oral presentations presented at the Congress. Adana: Çukurova University.

[17] Grossman, P.L. (1990). The making of a teacher: teacher knowledge and teacher education. New York: Teachers College Press.

[18] Tamir, P. (1988). Subject matter and related pedagogical knowledge in teacher education. Teaching and Teacher Education, 4(2), 99-110.

[19] ArslanKilcan, S.(2006).. The levels of elementary mathematics teachers' conceptual knowledge of the division with fractions (Unpublished master's thesis). University of Abantİzzet Baysal, Bolu.

[20] Fernandez Balboa, J. M. \& Stiehl, J. (1995). Effective professor' pedagogical processes. Teaching and Teacher Education, 11, 293-306.

[21] Gökbulut, Y. (2010). Prospective primary teachers pedagogical content knowledge about geometric shapes (Unpublished doctoral dissertation). Gazi University Institute of Educational Sciences, Ankara

[22] Kaya, O. N. (2009). The nature of relationships among the components of pedagogical content knowledge of pre-service science teachers: 'ozone layer depletion' as an example. International Journal of Science Education. 31 (7), 961-988.

[23] Ball, D. L. (1990). The mathematical understandings that prospective teachers bring to teacher education. The Elementary School Journal, 90(4), 449-466.

[24] Bonotto, C. (2003). About students' understanding and learning of the concept of surface area. Learning and teaching measurement, 157-167.

[25] Doğan, A., (2001). A research on misconceptions and mistakes of the students and their attitudes towards the trigonometry subject which are teaching in the high schools. (Unpublished doctoral dissertation). Selçuk University Institute of Sciences, Konya

[26] Gökkurt, B. (2014). An examination of secondary school mathematics teachers' pedagogical content knowledge on geometric shapes (Unpublished doctoral dissertation). Atatürk University Institute of Educational Sciences, Erzurum.

[27] Kohlbacher, F. (2006). The use of qualitative content analysis in case study research. Forum: Qualitative Social Research $7(1), 21$.

[28] Creswell, J.W. (2013). Qualitative inquiry and research design: Choosing among five approaches. CA: SAGE.

[29] CansızAktaş, M. (2014). Qualitative data collection tools. M. Metin (Eds.), Scientific research methods in education from theory to practice (337-371). Ankara: Pegem Academy.

[30] Yıldırım, A. \&Şimşek, H. (2013). Qualitative research methods in social sciences (8th. Edt). Ankara: Seçkin Publishing.

[31] Çakmak, Z., Konyalığlu, A. C., veIşık, A. (2014). The Investigation of Pre-Service Elementary Mathematics Teachers' Content Knowledge on Three Dimensional Objects. Middle Eastern ve African Journal of Educational Research MAJER, 8, 28-44.

i This article was presented at ICME-13 as an oral presentation 